\title{
Authorship Arabic Text Detection According to Style of Writing by using (SABA) Method
}

\author{
Tareef Kamil Mustafa ${ }^{1}$, Ammar Adil Abdul Razzaq ${ }^{1}$, Ehsan Ali Al-Zubaidi1 ${ }^{1, *}$ \\ ${ }^{1}$ College of Science \\ University of Baghdad, Iraq \\ ${ }^{2}$ Faculty of Physical Planning \\ University of Kufa, Iraq \\ * Corresponding author's email: Ihsana.kareem [AT] uokufa.edu.iq
}

\begin{abstract}
Authorship attribution of a style of writing is a method depend on analyzing texts in text mining, e.g., historical books and novels that famous authors wrote, attempted to measure the author's style, by choosing some attributes that show the author manner of writing. Assuming that these writers have a different way of writing that no other writer have; thus, authorship attribution is the essential of identifying the author of a given text [1].
\end{abstract}

Keywords--- Authorship Attribution; Style of writing; text mining

\section{INTRODUCTION}

In computer science, there is a field called "Text mining" that was taken from Data mining. To be more specific, in the authorship investigation using the style of the author, we use a sub- field of text mining called "Authorship attribution" and "Stylometric Text mining". All these subjects need to be defined to get the picture well clarified.

\subsection{Arabic Text Mining}

Text Mining is found newly. Formerly it is an unknown information automatically extracting from different written resources. A key element relates the extracted information together to form new facts or new hypotheses to be discovered further by more traditional means of experimentation. In searching, the user is exemplary looking for something that is already recognized and has been written by another person. The problem is pushing aside all the materials that nowadays isn't relevant to your needs to find the related information. At variance what's in text mining, the goal is to invent anonymous information, something that no one yet knows and so could not write so far[2].

Arabic is considered one of the very spoken languages in the world. In fact it a basic language in the Arab nations as well as a secondary language in many other nations. The language alphabet consists of 28 letters plus special character and punctuation symbols, which is. Moreover, the writing direction in Arabic is from right to left[3]. The manner of writing letters in a word changes depending on the location of the letter within the word. So, if the letters come at first, middle or at the end of the word, the letter forms changes. Lastly, there are diacritics in Arabic that are symbols placed above or below the letters to reduplication the letter in the pronunciation or to give short vowels. The most researchers in Arabic text applied learning algorithms only designed for English text without making salient changes[4].

One main problem associated with Arabic text classification the lack of standardized published Arabic and also infrequent. Such works can be used as key data sets for researchers in related fields to compare the results. Actually, most of the related research articles obtain data from online newspapers and websites. Such works ordinarily do not publish their data for other researchers to utilize. therefore the trust in the results derived from such experimental studies is not high enough [5]

However, researchers concluded that Arabic text classification is a very challenging task due to language complexity. 


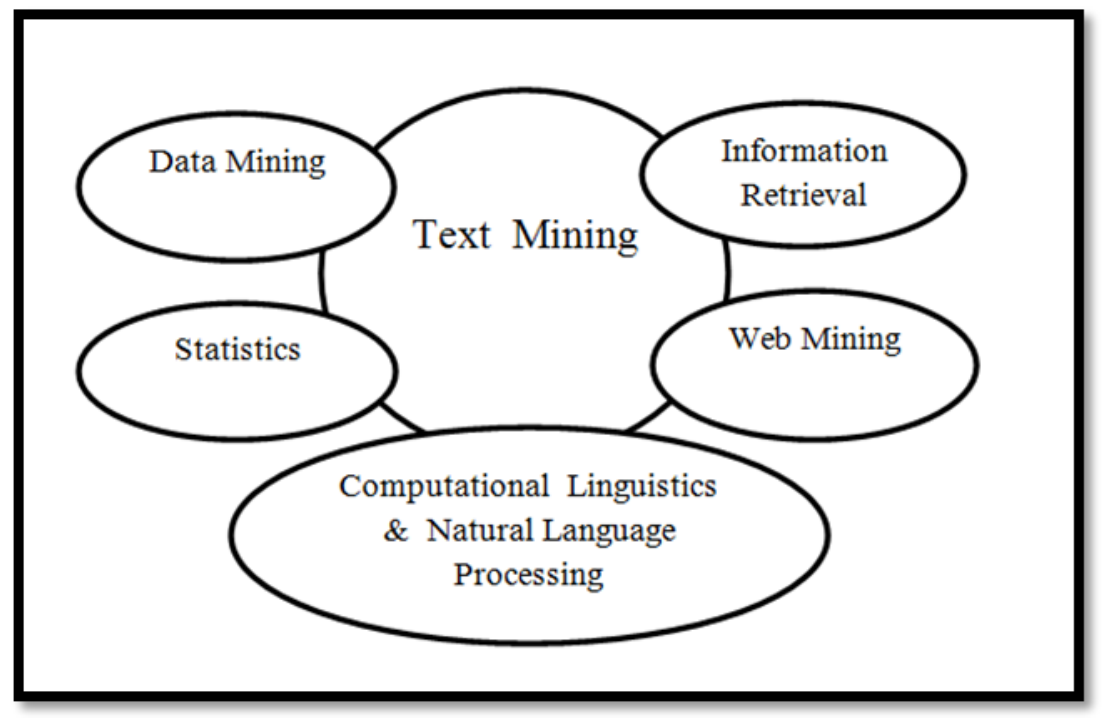

Figure 1: Relations of Text mining with other fields

\subsection{Authorship attribution $(\boldsymbol{A A})$}

: is the process of trying to identify the likely authorship of a given document, given a collection of documents whose authorship is known. Most of the approaches described in the research literature consist of two components, a comparison mechanism, and an indexing mechanism. The indexer converts each document to a set of tokens whose properties are assumed to be characteristic in some way of a certain author. The comparator uses these markers to assign an author to un-attributed documents [6].

\section{PROPOSED WORK}

In this paper we will measure the accuracy of Stylometric features, so it can be reduced nearly as well as fingerprints of different persons using authorship attributes.

The main aim is test algorithms supports a system of decision making enables users to predict in Arabic text and choose the right author for a specific unknown author's novel under consideration, by using a learning procedure to train the system the Stylometric map of the author and behave as an expert opinion[7]. Test the optimal threshold for authors of Arabic. Compare the effectiveness of many attributes in Arabic as the frequent, pair, trio sentence.

Still the word of frequent is a head of other attributes that give good results in the researches and experiments and still the best parameter and technique that's been used until now is the counting of the bag-of-word with the maximum item set[8].

Here we will focus on literature written in Arabic language and work on analysis of Arabic text based on the words redundancy as a feature in Arabic books as a frequent, pair and trio-of-words and test results obtained using text mining by computer-assisted authorship attribution is to define a certain characterization of documents that captures the writing manner of authors [9].

We proposed here if Stylometric Authorship Balanced Attribution (SABA) works with Arabic language as well as the attributes "frequent, pair, trio" considered as a constant in Arabic language, if we assumed that we need to threshold of "300" of frequent situations, and we check also the punctuation and symbols in Arabic if it were a good attributes type.

In addition to the difficulty of Arabic language, it is hard to get resources of Arabic books in text formatted.

\section{METHODOLOGY}

The proposed methodology is to test the algorithms (SABA )that was used in many of the research in different languages using statistical analysis and text mining, but here we will test this algorithm in the Arabic language, which have not been tested previously.

\subsection{Stylometric authorship attribution methodology}

The methodology of stylometric authorship attribution main steps can be shown in figure (2) which describes the process of converting readable text into the semi-structured data. 


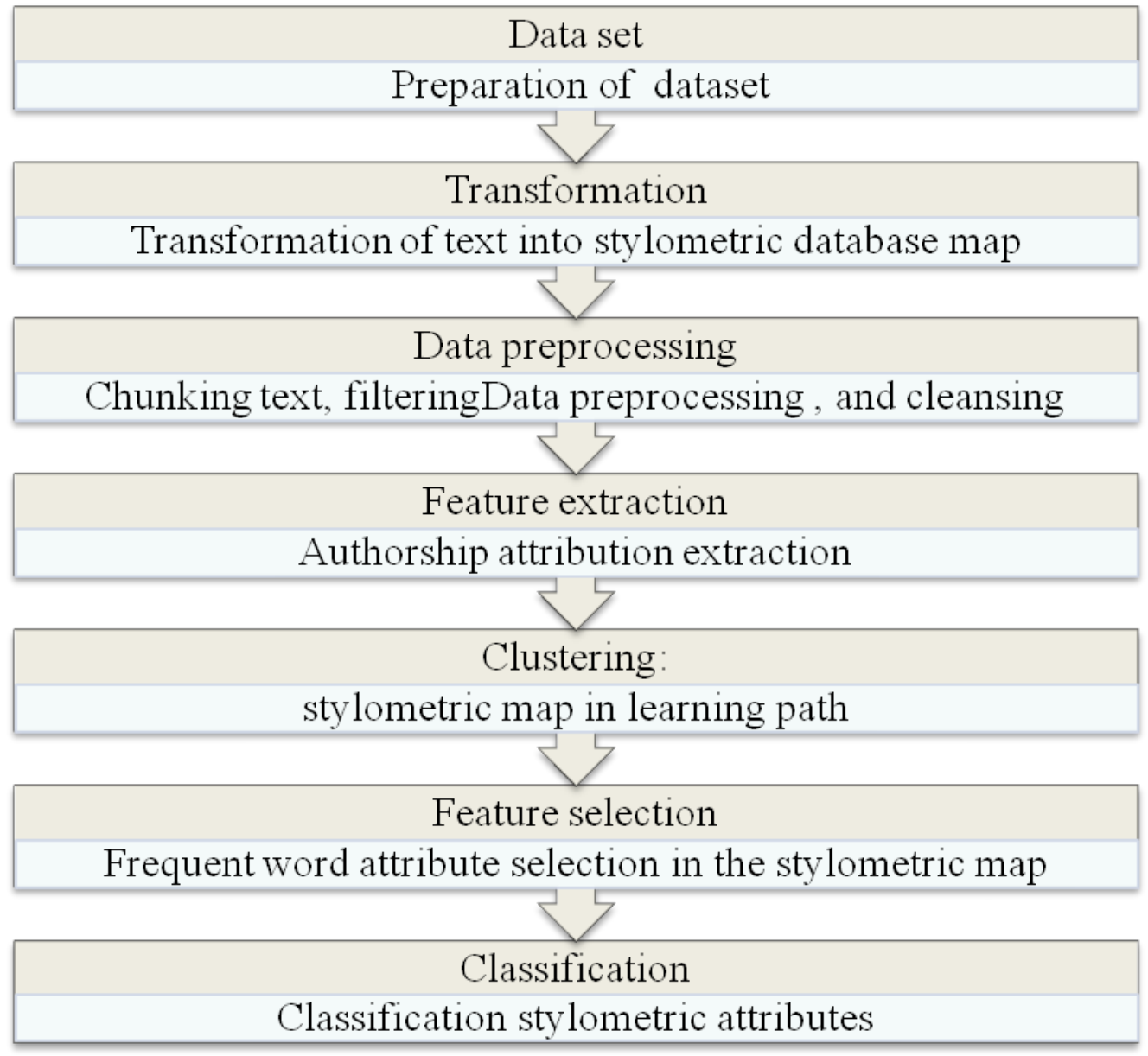

Figure (2): main steps for stylometric authorship attribution (SAA)

\subsection{Dataset}

This include dataset, Details of the dataset, and dataset plan.

\begin{tabular}{|c|c|c|}
\hline & & Table (1): Dataset \\
\hline No. & Name of Author & Number of Books \\
\hline 1 & ابن الجوزية - Ibnjuzia & 6 (5 for Learn, 1 for test) \\
\hline 2 & Sakhawy - السخاوي & 6 (5 for Learn, 1 for test) \\
\hline 3 & Tusi - الطوسي & 6 (5 for Learn, 1 for test) \\
\hline
\end{tabular}


Table (2): Details of the dataset

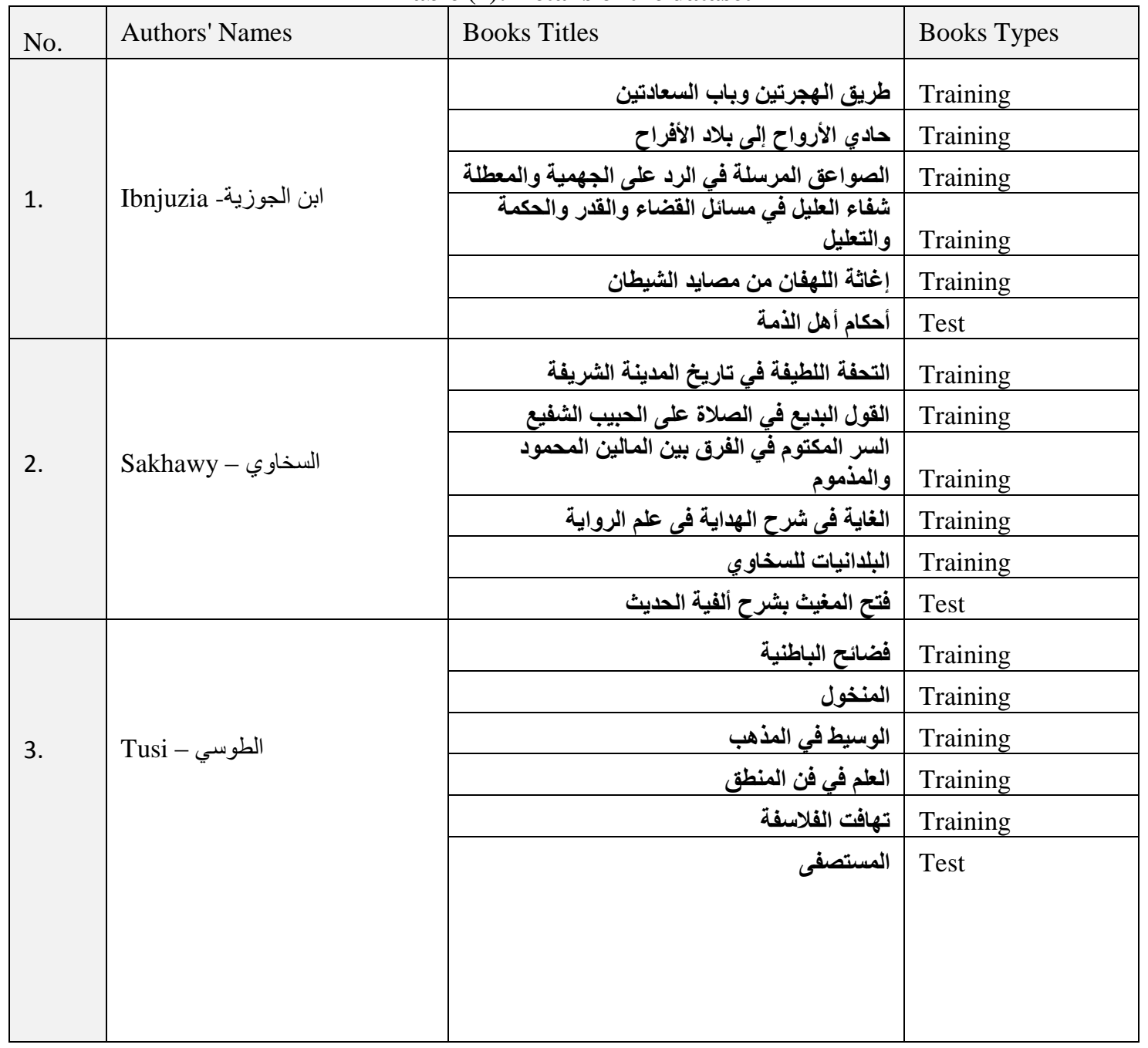

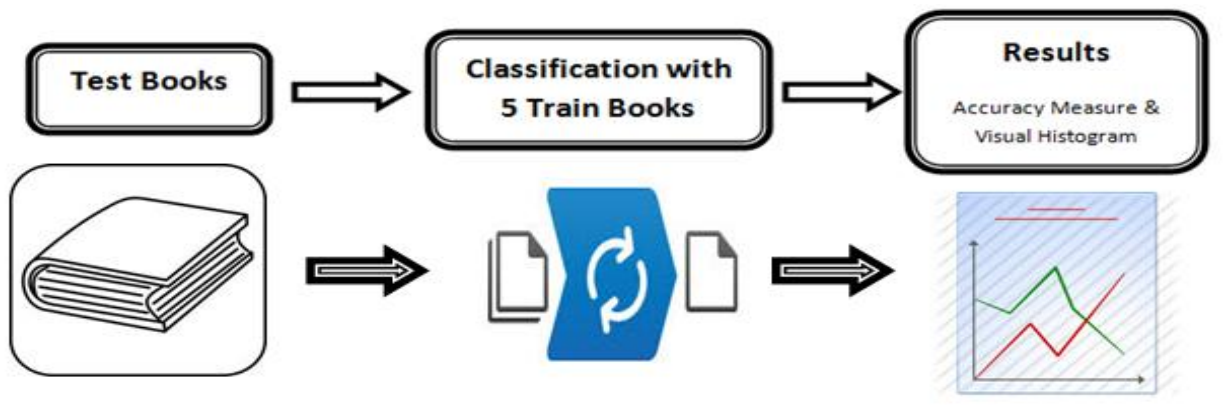

Figure (3): dataset plan

\subsection{Transforming text into stylometric database map}

The text transformation process contains chunking, filtering and cleansing text before finally transforming the text into database tuples, in this experiment, changing the data in separated tables which is represented by 3 tables for 5 books for each author respectively, repeating this transformed data process with single word, pair and trio words in the designed database, figure (4) represent a sample of the text and table (3) is representing the transformed text into separate database. 


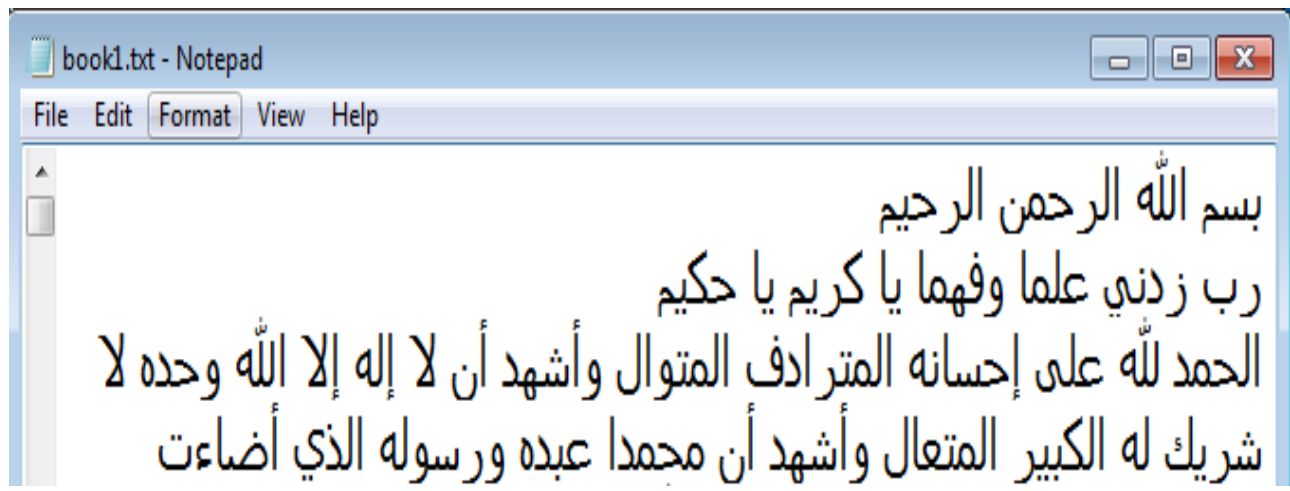

Figure (4): Sample of the textbook

Table (3): single word and pair and trio words

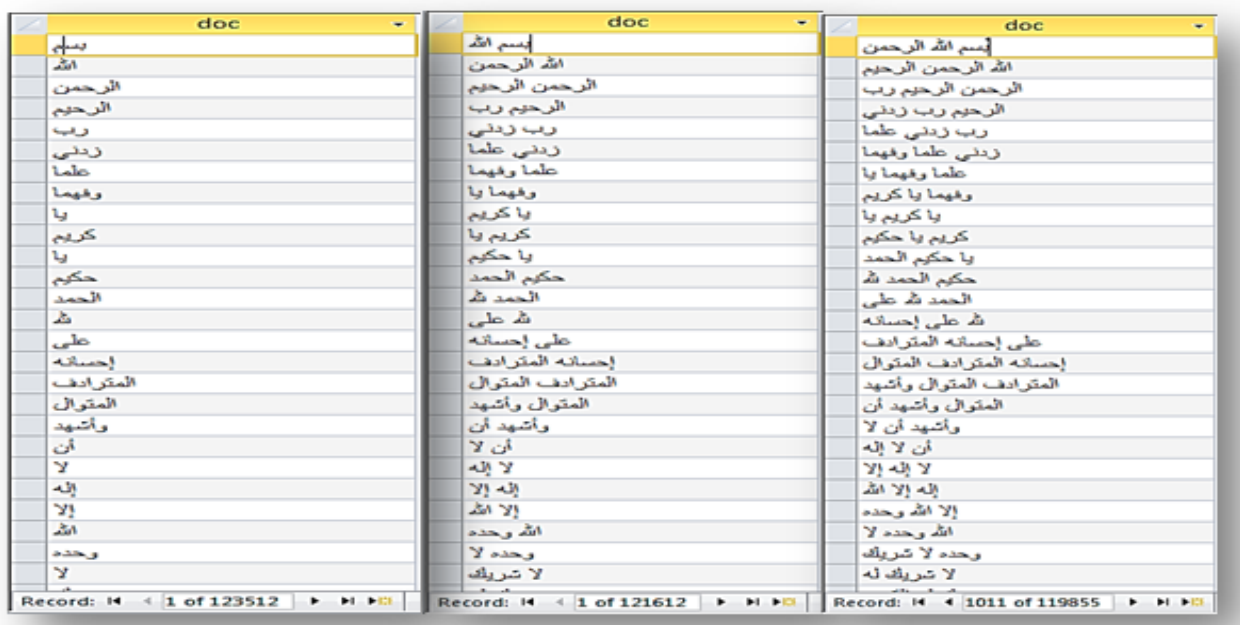

\subsection{Data pre-processing}

The most common procedures for preparing the data are cleansing and filtering, thus the data can be clearly analyzed without any distortion or noise. Cleaning and filtering operations includes all multi spaces found between the words (the fact that sentences consisting of several words that sometimes are separated by several spaces), multi punctuations, similar signs and titles of sections. Lastly, cleansing operations includes also the removal of the diacritics in Arabic that are symbols placed above or below, duplication symbol letters "الثدة to double the letter in the pronunciation or to give short vowels.

\subsection{Stylometric authorship attribution features extraction}

After a pre-process operation, which includes cleansing and filtering on data, the chunking operation starts on data that depends on the attribute type, whether it is single word, word pair or trio statement. The feature extraction step will be performed by collecting the redundancies of the features in the learning path and store the frequencies in the stylometric database map (SAA map), the SAA Map sorted in separated table, as shown in table (4). 
Table (4): descending attributes for a stylometric database map

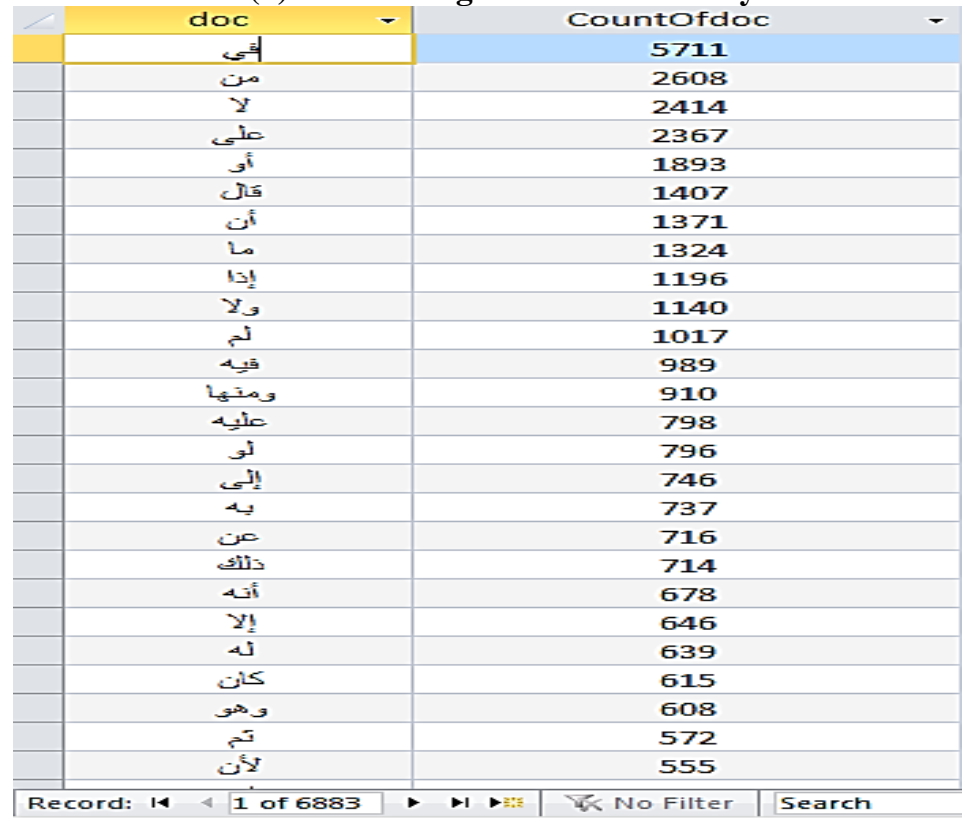

\subsection{Clustering Stylometric map}

After the completion of the cleansing. Chunking and analyzing in both learning and testing data, the data could be classified to represent the authorship attribution.

Clustering the SAA map is the most important step to differentiate the semantic authorship from the stylometric authorship because the semantics must be supported with some language rules and supported by a database annotated with frequent words or collocations. Whereas the stylometric method follows no prior rules, and it is language independent, so it will not have regards nor intentions to fit the grammatical rules of the language used under consideration.

The clustering in this the methodology is to measure the detection ability of the algorithm. The learning process during clustering uses 5 out of 6 books for each author, leaving one book for testing with the remaining books from 5 other authors.

After the completion of the clustering data for each set of training and testing books, the 300 attributes are selected as a result to compare the stylometric author attribution maps with testing books for each author, the 300 attributes in each author stylometric map usually chosen from thousands of high frequencies attributes through sorting, as a result, the stylometric map for each of the 3 suspected authors against 5 books under investigation will produce one author prediction for each investigated book.

\subsection{Attribute selection}

Attribute selection is based primarily on the number of frequencies that results from clustering the attributes, These features result from a group of five books for the purpose of making the stylometric map for each author, The sixth book is used for testing purposes.

Due to the different size of the books in this experiment, the percentage measure represents the number of frequencies for each attribute divided by the sum of frequencies for all attributes, and there is a weighted frequency for all used books was obtained.

By comparing the results between the learning data for a specific author and the testing data for all three authors, a comparison measure is needed to compare the accuracy. The statistical measure of Pearson correlation (r) will give weight to each attribute within the range $[-1,1]$.

The negative results are not common since there is always some relation between the author's style that results from the grammar rules. The comparison for choosing the favorite author will be resulted by the highest positive score that is achieved in the proposed algorithm.

The features were selected to give the nearest estimation between the Stylometric map of the author and other test maps. 


\subsection{Stylometric attributes classification}

After extracting the values of Pearson correlation for all authors, the values are grouped according to the equation called Winnow algorithm, as shown in equation (1).

$y=w 1 x 1+w 2 x 2+w 3 x 3+\ldots+w n x n$

Where $\mathrm{x}$ here is the classifier that used to assign parameter, hence wrong authors have the value of negative and the correct author have the value positive, $\mathrm{n}$ is a number of test books or a number of predictions in the test $=5, \mathrm{y}$ is the accuracy measure that describes the fitness between the authors map, and the test book under investigation. Lastly, we can be represented by using the computational stylometric measure of Pearson correlation, which is used to find the weight for each classifier in order to produce the final automated result.

Finally, to get a ratio result, the accuracy measure is separated between real positive (correct prediction) and negative (wrong prediction), the amount of negative books' weight should equal the weights of the positive authors.

\section{RESULT}

\subsection{Testing SABA method}

(SABA) method is considered an expansion of Burrow-Delta method, SABA method depends on the coefficient of variance $(\mathrm{CV})$, represented as a measurement of statistical that is not affected by the observation of mean, SABA method formerly tested in English language with high prediction, this research will examine and test this algorithm in Arabic language in the single, pair and trio words.

In SABA method, the test of single, pair and trio words is comparable to the Burrow Delta method in application, but there is an essential difference between them, precisely when selecting the top of 300 attributes, these selections depends on the values of (C.V). The following example in trio words can explain the major steps of extracting the (C.V) and the method of selecting the required attributes.

To apply SABA method, all steps used in the Burrow Delta method are recurred then transform the final stylometric database map to Microsoft Excel, by using the ready functions to elicit the values of the average, the standard deviation $(\sigma)$ and the (C.V) for each attributes in the data learning step, the (C.V) can be found by dividing the $(\sigma)$ by the $(\mu)$ itself, Finally, we sort the data in ascending order based on the values of the (C.V) and select the top 300 attributes, as shown in table (5).

\section{Table (5): SABA stylometric map}

\begin{tabular}{|c|c|c|c|c|c|c|c|c|}
\hline Doc & $\begin{array}{c}\text { Book1 after } \\
\text { percent }\end{array}$ & $\begin{array}{c}\text { Book2 after } \\
\text { percent }\end{array}$ & $\begin{array}{c}\text { Book3 after } \\
\text { percent }\end{array}$ & $\begin{array}{c}\text { Book4 after } \\
\text { percent }\end{array}$ & $\begin{array}{c}\text { Book5 after } \\
\text { percent }\end{array}$ & $\begin{array}{l}\text { Average } \\
\text { percent }\end{array}$ & CV & SD \\
\hline عبد الزرحمن & 88.23909671 & 74.24033148 & 16.90276883 & 94.71585244 & 106.018594 & 76.0233287 & 283 & 34.9884661 \\
\hline الخليفة & 12.4978452 & 632596685 & 7.244043786 & 9.94017946 & 524221171 & 10.96777726 & 50.335022 & 5.5206331 \\
\hline عبد اللهُ بن & 177.5555939 & 0.78729282 & 58.75724404 & 99.4017946 & 38.1340727 & 148.92711996 & 53.6772198 & 79.9399803 \\
\hline بن عبد الزحمن & 66. & 06 & 786 & 379 & 408 & 585 & 58.6 & 1584 \\
\hline ين عبد الكه & 115.605681 & 34.53038674 & 24.95170637 & 124.6261216 & 125.5912575 & 85.06090808 & 59.6783612 & 50.7629559 \\
\hline عن ابن عبأس & 2.585761076 & 13.8121547 & 9.658725048 & 24.92522433 & 13.04844234 & 12.8060615 & 63.2350685 & 8.09792176 \\
\hline ملفى الته عليه & 136.5066368 & 549.0331492 & 885.3831294 & 817.5473579 & 221.8235198 & 522.0587586 & 64.8753938 & 338.687675 \\
\hline عن عبد النه & 8.619203586 & 20.71823204 & 6.439150032 & 19.94017946 & 37.51427173 & 18.64620737 & 66.3111325 & 12.3645113 \\
\hline و عبد الثُ بن & 23.70280986 & 10.35911602 & 0 & 19.94017946 & 26.09688468 & 16.01979801 & 67.2764884 & 10.7775575 \\
\hline المشبرب & 7.541803137 & 12.08563536 & 5.634256278 & 0 & 6.524221171 & 183189 & 68.1968794 & 4.33540055 \\
\hline لا بأس بـ & 7.326323048 & 6.906077348 & 7.244043786 & 14.9551346 & 0 & 7.286315756 & 72.6384046 & 5.29266352 \\
\hline محمد بن عبد & 38.89415618 & 13.8121547 & 7.244043786 & 64.80558325 & 83.18381993 & 95175 & 78.1710292 & 32.5097297 \\
\hline اللى غِير ذالتك & 1.508360627 & 10.35911602 & 4.829362524 & 19.94017946 & 6.524221171 & 8.632247961 & 82.0182937 & 7.08002248 \\
\hline من هذا الوجه & 0.323220134 & 12.08563536 & 4.829362524 & 19.94017946 & 8.155276464 & 9.066734789 & 82.2740417 & 7.45956916 \\
\hline
\end{tabular}

After building relationships between the final stylometric map and the five test books for all authors, we obtain on the final trio test in SABA method, as shown in table (6). 
Table (6): Final trio test in SABA method

\begin{tabular}{|c|c|c|c|c|c|c|c|c|}
\hline Doc & $\begin{array}{l}\text { Average } \\
\text { percent }\end{array}$ & CV & SD & $\begin{array}{c}\text { Sakhawy } \\
\text { after } \\
\text { percent }\end{array}$ & $\begin{array}{c}\text { Suti after } \\
\text { percent }\end{array}$ & $\begin{array}{c}\text { Tusi after } \\
\text { percent }\end{array}$ & Pearson & Authors \\
\hline عبد الزحمن بن & 76.0233287 & 46.0233283 & 34.9884661 & 38.09605342 & 0 & 0 & 0.98761952 & sakhawy \\
\hline الخلِفِة & 10.96777726 & 50.335022 & 5.5206331 & 10.27309306 & 5.102040816 & 0 & 0.919806137 & suti \\
\hline عبد الفُ بن & 148.92711996 & 53.6772198 & 79.9399803 & 128.8417088 & 0 & 0 & 0.628330476 & tusi \\
\hline بن عبد الزحصن & 38.96601585 & 58.6805141 & 22.8654584 & 23.11445938 & 0 & 0 & & \\
\hline بن عبد النه & 85.06090808 & 59.6783612 & 50.7629559 & 63.77878606 & 6.802721088 & 0 & & \\
\hline عن أين عبأن & 12.8060615 & 63.2350685 & 8.09792176 & 17.97791285 & 5.102040816 & 0 & & \\
\hline صلخي النه علديه & 522.0587586 & 64.8753938 & 338.687675 & 413.9200411 & 141.1564626 & 37.56574005 & & \\
\hline عن عبد الثها & 18.64620737 & 66.3111325 & 12.3645113 & 17.97791285 & 0 & 0 & & \\
\hline وعبد النّ بن & 16.01979801 & 67.2764884 & 10.7775575 & 14.12550295 & 0 & 0 & & \\
\hline المشبِِب & 6.357183189 & 68.1968794 & 4.33540055 & 12.41332078 & 0 & 0 & & \\
\hline لا بأس بـ & 7.286315756 & 72.6384046 & 5.29266352 & 11.98527523 & 0 & 0 & & \\
\hline هحمد ين عبد & 41.58795175 & 78.1710292 & 32.5097297 & 24.82664155 & 0 & 0 & & \\
\hline الى عبر ذالك & 8.632247961 & 82.0182937 & 7.08002248 & 10.7011386 & 0 & 22.53944403 & & \\
\hline من هذا الوجه & 9.066734789 & 82.2740417 & 7.45956916 & 2.568273264 & 0 & 0 & & \\
\hline
\end{tabular}

By getting on the weights for each parameter, multiply each Pearson value by -1 if it is the wrong author for the formerly known result or by +1 if it is the right author, as shown in table (7).

Table (7): Final SABA results

\begin{tabular}{|lllll|}
\hline Author name & $\begin{array}{l}\text { Pearson } \\
\text { (Sakhawy) }\end{array}$ & weight & sign & Result \\
\hline Sakhawy & 0.976621 & 4 & 1 & 3.90648 \\
\hline Suti & 0.896984 & 1 & -1 & -0.897 \\
\hline Tusi & 0.626008 & 1 & -1 & -0.626 \\
\hline SABA RESULT & & & \multicolumn{2}{c|}{$\mathbf{2 . 3 8 3 4 8}$} \\
\hline
\end{tabular}

\section{CONCLUSION}

Stylometric authorship balanced attribution (SABA) that is able to forecast with higher accuracy and independent from human judgments, which means that the approach does not rely on the domain experts. This method implemented by merging three methods, which are called the computational method ,the Burrows-delta method, and the algorithm of Winnow. Stylometric authorship balanced attribution (SABA) method also uses a set of more effective attributes in comparison with frequent words method. This leads in higher Stylometric prediction thus far, having more accurate for author artistic writing style for authorship recognition and prediction. The effective attributes are represented by the frequent word, pair and the trio, while both are multiple words attributes.

The SABA method is compared against three other approaches using the computational method, the Burrows-delta method, and the Winnow algorithm method. The results showed that the SABA method produces superior prediction accuracy and even provides a completely correct result during the final phase of the experiment.

\section{REFERENCES}

[1] Argamon, S. and S. Levitan, 2005. Measuring the usefulness of function words for authorship attribution. Proceeding of the Joint Conference on Association for Literary and Linguistic Computing Computer Humanities, June 16-19, University of Victoria, Canada, pp: 2-4. http://lingcog.iit.edu/doc/paper_162_argamon.pdf.

[2] Mofleh Al-diabat (2012), “ Arabic Text Categorization Using Classification text Mining”, Department of Computer science /Al Albayt University. Applied Mathematical Sciences, Vol. 6, 2012, no. 81, 4034 - 4047.

[3] Zaho Y., Zobel J. (2008), "Search with manner: Authorship Attribution in Classic Literature", the Thirtieth Australasian Computer Science Conference, Ballarat, Jan. 2007.

[4] J. F. Burrows, "Delta: a gauge of stylistic difference and an index to likely authorship," Literary and Linguistic Computing 17, pp. 268-288, 2002.

[5] D. Hoover, "Delta prime" Literary and Linguistic Computing 19.4, pp. 478-496, 2004.

[6] D. Hoover, "Testing burrows' delta," Literary and Linguistic Computing 19.4, pp. 454-476, 2004.

[7] J. Burrows, "The English of Juvenal: Computational stylistics and translated texts," Style 36, pp. 678-700, 2002.

[8] Sterling Stein and Shlomo Argamon (2007), “A Mathematical Explanation of Burrows's Delta”, Linguistic Cognition Laboratory Department of Computer Science Illinois Institute of Technology Chicago.

[9] S. K.-M. J. Higgins, Concepts in Probability and Stochastic Modelling. Duxbury Press, 1 ed., 1995. 